\title{
Integrating data from physical and social science to address emerging societal challenges
}

\author{
Zachary A. Collier ${ }^{1}$. James H. Lambert ${ }^{2} \cdot$ Igor Linkov $^{3}$
}

Published online: 18 August 2021

(C) The Author(s), under exclusive licence to Springer Science+Business Media, LLC, part of Springer Nature 2021

\section{Introduction}

This issue of Environment Systems and Decisions explores the role of integrating physical and social science to address societal challenges. Interconnectedness and globalization results in an inability to optimize systems by looking at their components alone, which is the "engineering approach" typically used in physical science. At the same time, a sole focus on socio-political factors may not be useful if it decouples from data-driven approaches. The COVID-19 crisis specifically highlighted the need for methodological fusion of physical and social science in addressing complex systems (Linkov et al. 2021). Diverse papers presented in this issue draw upon methodologies from fields such as decision analysis and machine learning, which are capable of synthesizing disparate data sources and multiple lines of evidence. The most pressing societal challenges tend to involve technological, social, physical, economic, and other inputs to effectively address, making the methodologies described in this issue a natural fit. The articles in this issue present novel approaches to issues including ecological management, public health, sustainability, and enterprise risk management. Incorporating physical and social information into decision making can ensure that these emerging challenges are addressed holistically.

First, in a perspectives article, Whelshula et al. (2021) discussed the opioid crisis among native populations through

Igor Linkov

igor.linkov@usace.army.mil

Zachary A. Collier

zcollier@ radford.edu

James H. Lambert

lambert@virginia.edu

Radford University, Radford, VA, USA

2 University of Virginia, Charlottesville, VA, USA

3 US Army Engineer Research and Development Center, Concord, MA, USA the lens of resilience, distinguishing between positively and negatively resilient systems. The authors explored the role of several social institutions and mechanisms in disrupting patterns of negative resilience. In a review article, Cantelmi et al. (2021) described the use of qualitative methodologies within the field of critical infrastructure resilience. Their findings identified four principle dimensions of critical infrastructure resilience: techno-centric, organizational, community, and urban. Cai et al. (2021) developed an expected utility model to aid in natural hazard risk assessment. The authors applied this model to the pricing of property insurance products. Moving from the insurance sector to the construction sector, Sparrevik et al. (2021) investigated how the principles of the circular economy have been applied to construction. Using systems thinking as a framework, they found that circular economy principles are applied at various levels within products, organizations, and systems. Eregowda et al. (2021) studied the impacts of lockdowns and work-from-home arrangements on air quality. Their investigation found that particulate matter was reduced due to less traffic, and that working from home two days per week could reduce the emissions of various greenhouse gasses by several tons per year. Morgan et al. (2021) developed a multicriteria decision analysis methodology to compare available alternatives to reduce exposure to mercury resulting from gold mining. Twelve alternatives were assessed, and decision trees were incorporated to allow for the consideration of location-specific factors. In a study on ecological health, Sedighkia et al. (2021) created a habitat simulation model based on a genetic algorithm. The model's objective was to minimize habitat loss and was applied to a dam diversion project as a case study. Following the theme of decision support for technological decisions, Ossei-Bremang and Kemausuor (2021) described a multicriteria decision support tool for the selection of sustainable energy production alternatives. In their case, they applied the tool to sustainable biomass selection. Hirschberg and Lye (2021) analyzed the impact of reference day variation and return rate volatility on 


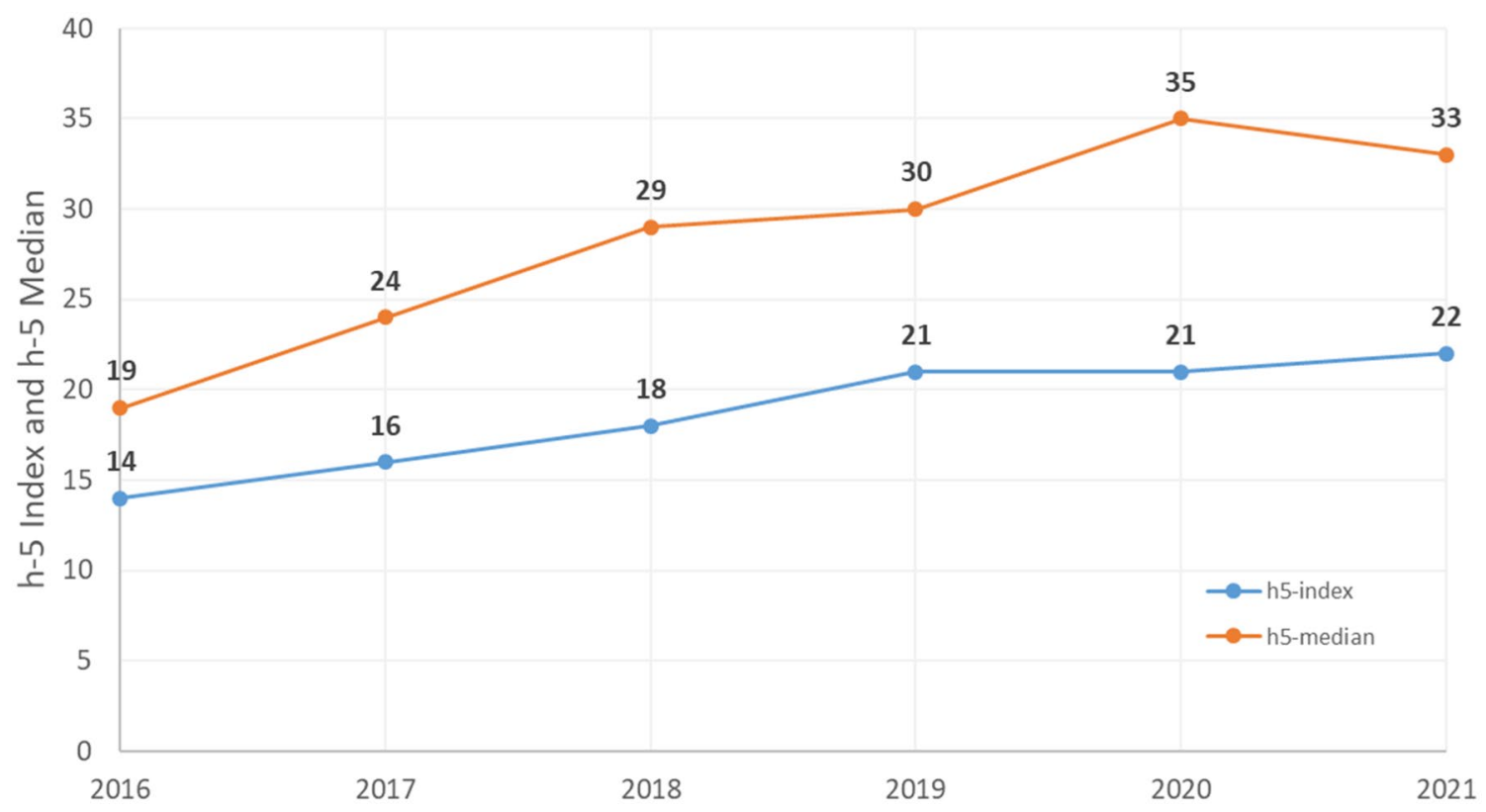

Fig. 1 Trends in Google Scholar Metrics for Environment Systems and Decisions

the estimation of the beta value used in the capital asset pricing model, a commonly used financial model. The authors applied a resampling technique for monthly rates of return to account for these sources of error. Lastly, Miller and GriffyBrown (2021) explored the role of risk and opportunity in enterprise risk management, noting that risk and reward must be properly balanced within an organization. A risk optimization system was devised by the authors to account for both risks and rewards.

Google Scholar recently published their 2021 metrics, including the h-5 index and h-5 medians, which cover journal performance over the previous 5 years. Environment Systems and Decisions received an h-5 index of 22 and an h-5 median of 33. The trends since 2016 are plotted in Fig. 1. These trends show an upward trajectory in terms of the reach and impact that Environment Systems and Decisions is making within the scholarly community.

Figure 2 shows a collection of metrics from Scimago's journal rankings page for Environment Systems and Decisions. ${ }^{1}$ Since the journal's first year as the newly-rebranded Environment Systems and Decisions in 2013, once can see a sharp increase in total citations and citations per document. Scimago's SJR metric, which calculates the "average prestige per article" has also been steadily increasing. The journal was ranked in the second quartile for journals in the category of "Environmental Science (Miscellaneous)" for the fifth consecutive year.

The Editorial Board would like to thank all of the authors for submitting their high-quality research to the journal, the reviewers who have provided meaningful and constructive

\footnotetext{
$\overline{1}$ https://www.scimagojr.com/journalsearch.php?q=21100224426\& tip $=$ sid
} 


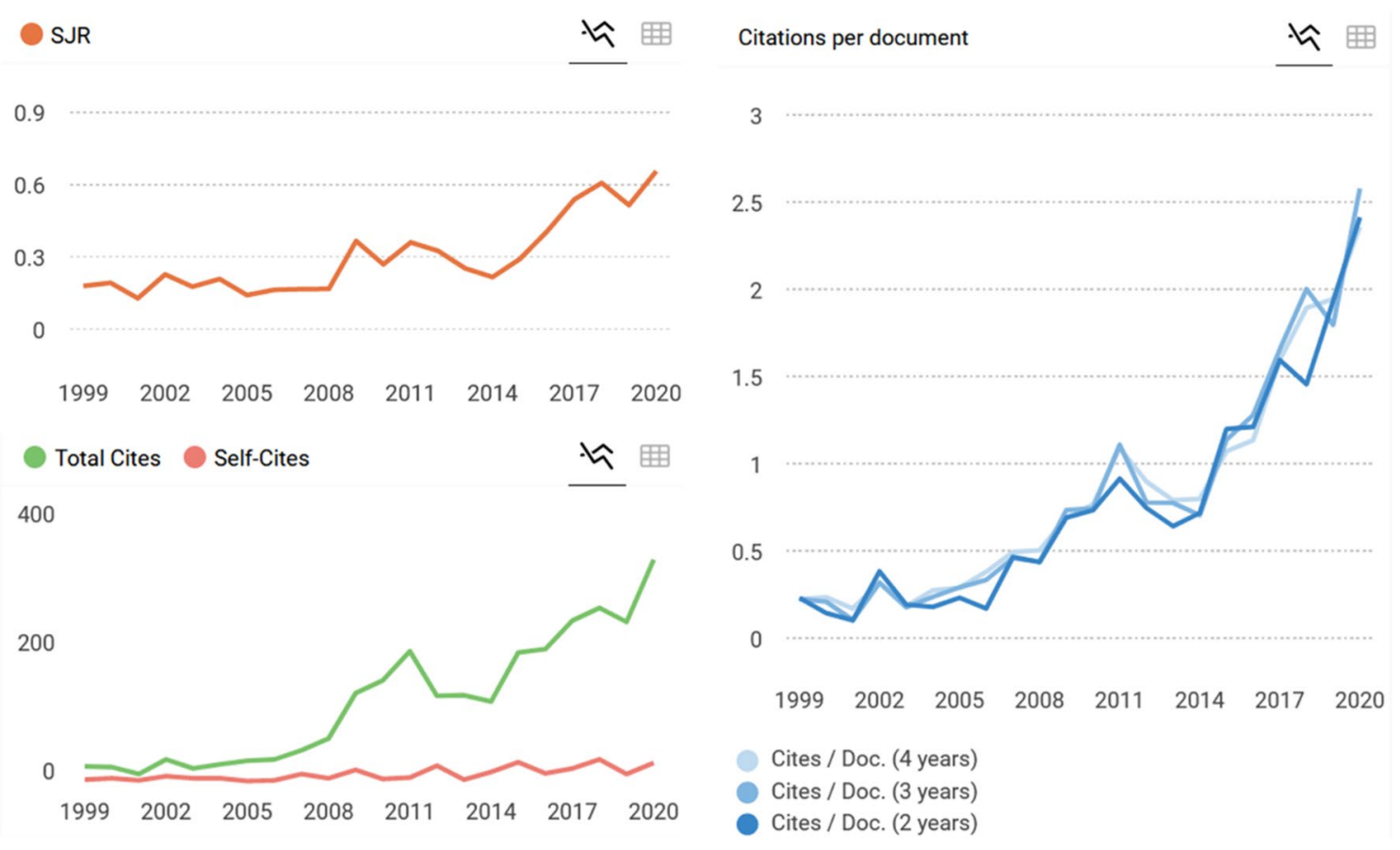

Fig. 2 Selected journal metrics from Scimago

feedback, and the Springer staff who work diligently behind the scenes to support all facets of the publication process.

\section{Declarations}

Conflict of interest The authors declare that they have no conflict of interest.

\section{References}

Cai M, Xiu W, Wei G (2021) Expected loss utility for natural hazards and its application in pricing property insurance products. Environ Syst Decis. https://doi.org/10.1007/s10669-021-09797-0

Cantelmi R, Di Gravio G, Patriarca R (2021) Reviewing qualitative research approaches in the context of critical infrastructure resilience. Environ Syst Decis. https://doi.org/10.1007/ s10669-020-09795-8

Eregowda T, Chatterjee P, Pawar DS (2021) Impact of lockdown associated with COVID19 on air quality and emissions from transportation sector: case study in selected Indian metropolitan cities. Environ Syst Decis. https://doi.org/10.1007/s10669-021-09804-4

Hirschberg J, Lye J (2021) Estimating risk premiums for regulated firms when accounting for reference-day variation and high-order moments of return volatility. Environ Syst Decis. https://doi.org/ 10.1007/s10669-021-09812-4
Linkov I, Keenan J, Trump BD (2021) COVID-19: systemic risk and resilience. Springer, Amsterdam

Miller H, Griffy-Brown C (2021) Evaluating risk for top-line growth and bottom-line protection: enterprise risk management optimization (ERMO). Environ Syst Decis. https://doi.org/10.1007/ s10669-021-09819-x

Morgan VL, McLamore ES, Correll M, Kiker GA (2021) Emerging mercury mitigation solutions for artisanal small-scale gold mining communities evaluated through a multicriteria decision analysis approach. Environ Syst Decis. https://doi.org/10.1007/ s10669-021-09808-0

Ossei-Bremang RN, Kemausuor F (2021) A decision support system for the selection of sustainable biomass resources for bioenergy production. Environ Syst Decis. https://doi.org/10.1007/ s10669-021-09810-6

Sedighkia M, Abdoli A, Datta B (2021) Optimizing monthly ecological flow regime by a coupled fuzzy physical habitat sumulationgenetic algorithm method. Environ Syst Decis. https://doi.org/10. 1007/s10669-021-09809-z

Sparrevik M, de Boer L, Michelsen O, Skaar C, Knudson H, Fet AM (2021) Circular economy in the construction sector: advancing environmental performance through systemic and holistic thinking. Environ Syst Decis. https://doi.org/10.1007/ s10669-021-09803-5

Whelshula M, Hill M, Galaitsi SE, Trump B, Mahoney E, Mersky A, Poinsatte-Jones K, Linkov I (2021) Native populations and the opioid crisis: forging a path to recovery. Environ Syst Decis. https://doi.org/10.1007/s10669-021-09813-3 